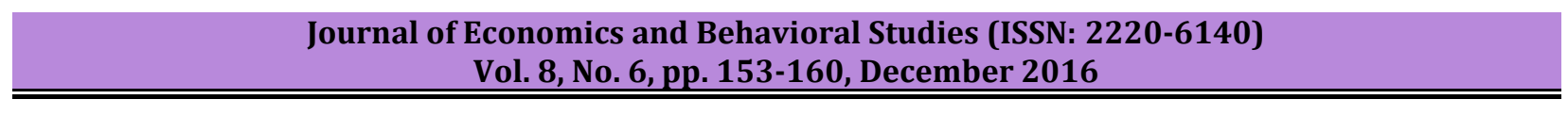

\title{
Modelling Volatility Persistence and Asymmetry with Structural Break: Evidence from the Nigerian Stock Market
}

\author{
Aluko Olufemi Adewale ${ }^{1}$, Adeyeye Patrick Olufemi ${ }^{2 *}$, Migiro Stephen Oseko \\ ${ }^{1}$ University of Ilorin, Ilorin, Kwara State, Nigeria \\ ${ }^{2}$ University of KwaZulu-Natal, Westville, Durban, South Africa \\ olufemiadewale6@gmail.com, adeyeyepo@gmail.com*,stephen410@gmail.com
}

\begin{abstract}
This study contributes to existing literature on the Nigerian stock market by modelling the persistence and asymmetry of stock market volatility taking into account structural break. It utilises returns generated from data on monthly all-share index from January 1985 to December 2014. After identifying structural break in the return series, the study splits the sample period into pre-break period (January 1985 November 2008) and post-break period (January 2009 - December 2014). Using the symmetric GARCH model, the study shows that the sum of ARCH and GARCH coefficients is higher in the pre-break period compared to the post-break period, thus indicating that persistence of shock to volatility is higher before structural break in the market. The asymmetric GARCH model provides no evidence of asymmetry as well as leverage effect with or without accounting for structural break in the Nigerian stock market. This study concludes that the Nigerian stock market is characterised by inefficiency, high degree of uncertainty and nonasymmetric volatility.
\end{abstract}

Keywords: Persistence, asymmetry, stock market volatility, structural break

\section{Introduction}

The Nigerian stock market started trading on $15^{\text {th }}$ August, 1961. It ranks among the top African stock markets in terms of liquidity, market capitalisation and volume of transactions. The market is also a leading financial market for portfolio investment in Africa (Oloko, 2016). The International Finance Corporation (IFC) classifies the Nigerian stock market as an emerging stock market. Harvey (1995) argued that emerging stock markets are characterised by high volatility. Investors in the stock market are interested in the volatility of the stock market because of its implication on their investment. Stock market volatility is the uncertainty associated with returns on assets in the stock market. It is also an index for measuring the risky nature of the stock market. High volatility in the stock market impedes investment in stock assets. Shittu, Yaya and Oguntade (2009) suggested that high level of volatility could mean huge losses or gain, hence greater uncertainty. Persistence and asymmetry are two main phenomena associated with stock volatility. Investors' understanding of these phenomena is important in guiding them in portfolio management.

As observed from prior studies such as Atoi (2014), Adesina (2013), Emenike (2010), high volatility persistence is exhibited in the Nigerian stock market. However, evidence on the asymmetry of volatility in the Nigerian stock market is few and mixed. Also, modelling volatility with structural break has been largely ignored in the Nigerian stock market. According to Kumar and Maheswaran (2012), volatility of returns of financial assets tends to be highly affected by infrequent structural breaks as a result of domestic and global macroeconomic and political occurrences. Lamoureux and Lastrapes (1990) argued that volatility persistence is exaggerated if structural breaks are not considered. Investors tend to behave differently after structural break in the stock market because its occurrence may affect the persistence and asymmetry of stock market volatility. Failure to account for structural break in the stock market may lead to wrong inferences and portfolio decisions (Turtle \& Zhang, 2014). Therefore, this study models the persistence and asymmetry of the Nigerian stock market volatility with structural break. The rest of the paper follows the following order: Section 2 provides the literature review, Section 3 presents the data issues and preliminary analyses, Section 4 discusses the models and estimation and lastly, Section 5 concludes the study.

\section{Literature Review}

Theoretical Literature: The asset pricing theory assumes that investors are risk averse and risk-return relationship is positive and linear. This implies that if investors are risk averse, there is a positive correlation between volatility and returns in the stock market. In other words, risk-averse investors expect more returns 
on assets as volatility increases. As stock market volatility rises, investors demand higher compensation in form of higher risk premium. In contrast to the asset pricing theory, Li, Yang, Hsiao and Chang (2005) provided evidence of negative correlation between expected returns and stock market volatility. The asset pricing theory suggests that investors holding a well-diversified portfolio should consider systematic volatility (un-diversifiable risk) and completely ignore idiosyncratic volatility (diversifiable risk). Increased stock market volatility would lead to loss of consumer confidence and this would indirectly influence real consumption and investment decisions (Kupiec, 1991). Guo (2002) argued that increase in stock market volatility would increase the cost of equity capital (minimum rate of return desired by shareholders). N'dri (2007) discovered that volatility tends to be higher during market boom. However, Mele (2008) recognised that stock market volatility is higher during the recession period than the period of expansion. In periods of high stock market volatility, the difference between beta coefficients (systematic risk) of small and large companies becomes wider (Bundo, 2011).

The theory of excess stock market volatility presented by Gabaix, Gopikrishnan, Plerou and Stanley (2006) stated that volatility is as a result of trading by very large institutional investors in relatively illiquid markets. The excess volatility phenomenon in the stock market was first identified by Shiller (1981) and LeRoy and Porter (1981). Shiller (1981) described excess volatility as stock market volatility that cannot be explained by subsequent changes in dividends. According to Karolyi (2001), the presence of excess volatility in the stock market limits the ability to use stock prices as an indicator of the fundamental value of a firm. The asset pricing theory fails to explain excess volatility in the stock market. Also, the efficient market theory does not explain excess stock market volatility (Shiller 2003). It is believed that a stock market experiencing excess volatility is inefficient. Wang and Ma (2014) observed a positive association between stock returns and excess volatility.

Empirical Review: The empirical review focuses only on the Nigerian stock market and other African stock markets. Ndwiga and Muriu (2016) showed no evidence of leverage effect and high volatility persistence but found significant positive relationship between risk and return in the Kenyan stock market. Owidi and MugoWaweru (2016) showed that volatility is more persistent during the bullish period than bearish period in the Kenyan stock market. It also revealed that good news impact more on volatility during the bullish period while the impact of bad news on volatility is greater when the market is in a bearish phase. Coffie (2015) found that stock market volatility in Ghana and Nigeria is non-asymmetric, with leverage effect present only in the Ghanaian stock market. However, Boako, Agyemang-Badu and Frimpong (2015) observed that the Ghanaian stock market is characterised by volatility clustering, high volatility persistence and leverage effect. Atoi (2014) equally observed that volatility clustering, high volatility persistence and leverage effect do exist in the Nigerian stock market. Namugaya, Weke and Charles (2014) discovered that returns increase as volatility increases and bad news affect volatility more than good news in the Ugandan stock market. Osazevbaru (2014) found evidence of volatility clustering and high volatility persistence in the Nigerian stock market.

In addition, Niyitegeka and Tewari (2013) found that the South African stock market exhibits volatility clustering, high volatility persistence and non-asymmetric volatility. Adesina (2013) revealed that stock market volatility in Nigeria is highly persistent and non-asymmetric. Emenike and Aleke (2012) found mixed evidence of asymmetric volatility in the Nigerian stock market using two asymmetric volatility models. Furthermore, Abdalla and Winker (2012) showed that volatility is in excess in the Sudanese stock market but quite persistent in Egyptian stock market. The study also indicated that significant positive relationship between return and risk as well as leverage effect exist in both markets. Emenike (2010) showed that volatility is highly persistent and leverage effect is present in the Nigerian stock market. N'dri (2007) found volatility clustering, high volatility persistence and absence of leverage effect in the regional stock market of the West African Economic and Monetary Union (WAEMU). It also showed that the impact of good news on volatility is more than bad news and investors are not rewarded for assuming risk.

\section{Methodology}

Data Issues and Preliminary Analyses: Data on monthly all-share index of the Nigerian Stock Exchange (NSE) from January 1985 to December 2014 was gathered from the Central Bank of Nigeria (CBN) 2014 
annual edition of the Statistical Bulletin. The monthly all-share index represents stock price $(p)$. However, this study would be utilising returns as proxy for the stock market. Plethora of studies has used stock market return in modelling stock market volatility (i.e. Banumathy and Azhagaiah, 2015, Atoi, 2014, Ahmed and Suliman, 2011 and Goudarzi and Ramanarayanan, 2010). A plausible reason for this is that market investors are more concerned about return than price. Return $(r)$ is calculated as:

$$
r_{t}=\ln \left(\Delta p_{t}\right) * 100
$$

Where $r_{t}$ is the return at time $t$ or present return, $\ln$ is natural logarithm and $\Delta$ is the first difference operator.

Fig. 1: Graph of NSE Return (1985M1 - 2014M12)

RETURN

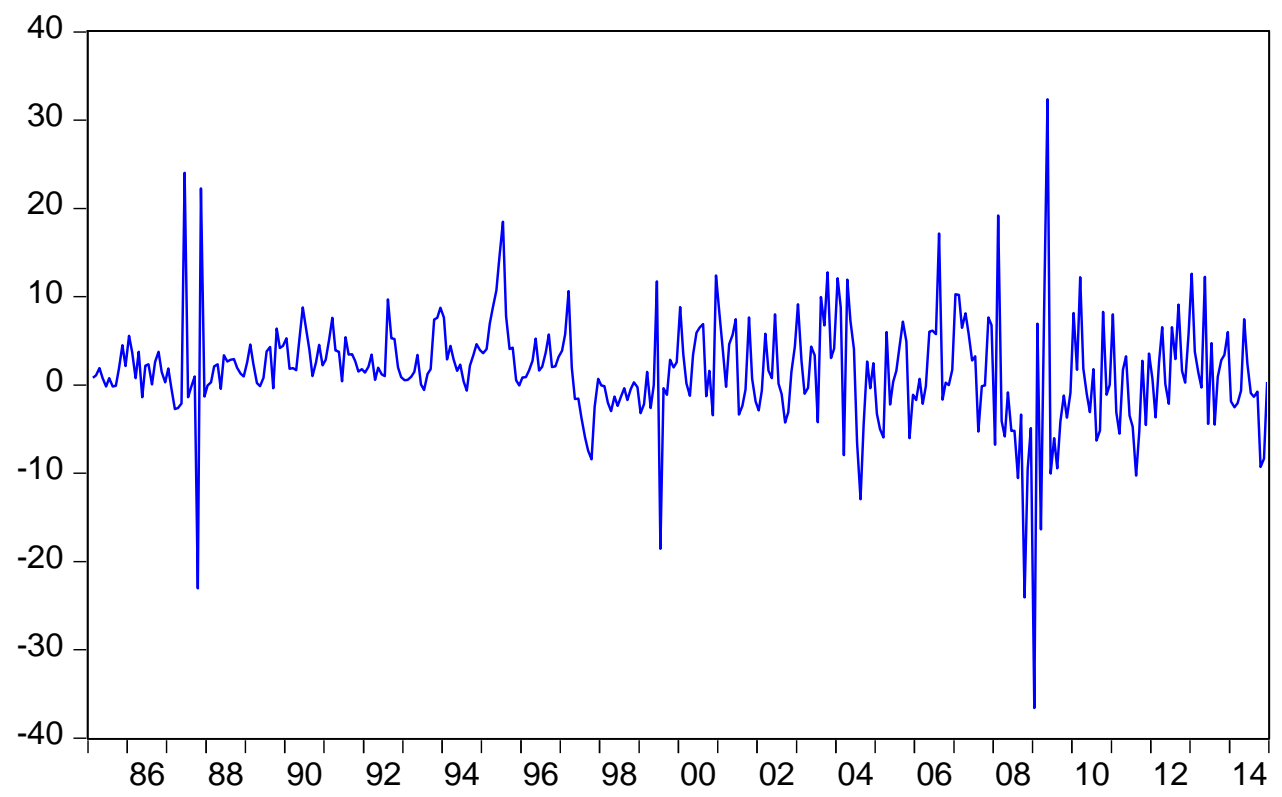

The Perron (2006) unit root test with structural break is used to endogenously determine the structural break period/point in an innovative outlier model. The test was performed using the $t$-statistic for the null hypothesis that $\delta=1$ in Equation 2:

$y_{t}=\mu+\rho D U_{t}+\beta t+\partial D T_{t}^{*}+\gamma D\left(T_{b}\right)_{t}+\delta y_{t-1}+\sum_{i=1}^{k} c_{i} \Delta y_{t-1}+\varepsilon_{t}$

With $D T_{t}^{*}=1\left(t>T_{b}\right)_{t}$. This study accounts for only one break point in the return series which is the most significant structural break in the market. Table 1 presents the result of the test for structural break.

Table 1: Structural Break Test Result

\begin{tabular}{lll}
\hline Coefficient & $\boldsymbol{t}$-statistic & Break Period \\
\hline-0.878141 & $-17.465641^{*}$ & $2008 \mathrm{M} 12$ \\
\hline
\end{tabular}

Note: * denotes rejection of null hypothesis at $1 \%$ critical value. Also, critical value for the test was obtained from Table 1(e) in Perron (1997).

Source: Authors' computation

\section{Results}

From Table 1, it is indicated that the break date in the return series is December 2008. This period corresponds with the highest spike period in Fig. 1. This structural break of this period is as a result of the global financial crisis. The crisis caused a structural break in the returns three months after it peaked in September 2008. On the basis of this break period, the study further splits the full sample period into two sub-sample periods namely pre-break period and post-break period. The pre-break period is January 1985 to November 2008 (1985M1-2008M11) and the post-break period is January 2009 to December 2014 
(2009M1-2014M12). Table 2 reports the descriptive and residual diagnostic statistics on the return series in the pre-break, post-break and full sample periods.

Table 2: Descriptive and Residual Diagnostic Statistics

\begin{tabular}{llll}
\hline Statistic & Pre-break & Post-break & Full \\
\hline Mean & 1.990494 & 0.134834 & 1.599173 \\
Median & 1.842266 & 0.058867 & 1.633574 \\
Maximum & 24.03743 & 32.35158 & 32.35158 \\
Minimum & -24.07990 & -36.58828 & -36.58828 \\
Standard Deviation & 5.379950 & 8.082176 & 6.055396 \\
Skewness & -0.266738 & -0.448002 & -0.499685 \\
Kurtosis & 8.296936 & 10.45728 & 10.93041 \\
Jarque-Bera & $337.7437^{*}$ & $169.2415^{*}$ & $955.6904^{*}$ \\
DF-GLS & $-7.918908 \ddagger^{\mathrm{p}}$ & $-8.31643 \ddagger^{\mathrm{n}}$ & $-6.084345 \ddagger^{\mathrm{n}}$ \\
ARCH LM(2) & $18.34782^{*}$ & $6.238325^{*}$ & $16.12161^{*}$ \\
ARCH LM(4) & $28.62677^{*}$ & $37.17726^{*}$ & $54.30781^{*}$ \\
Q-statistic(2) & $22.937^{*}$ & 0.1020 & $20.993^{*}$ \\
Q-statistic(4) & $27.620^{*}$ & 5.7441 & $32.405^{*}$ \\
$Q^{2}$-statistic(2) & $19.338^{*}$ & 2.7028 & $17.984^{*}$ \\
$Q^{2}$-statistic(4) & $26.254^{*}$ & $19.307^{*}$ & $74.051^{*}$ \\
Observations & 286 & 72 & 359 \\
\hline
\end{tabular}

Note: ${ }^{*}$ and ${ }^{* *}$ indicate null hypothesis rejected at $1 \%$ and $5 \%$ respectively, $\neq$ denotes $1 \%$ critical value and ${ }^{p}$ and ${ }^{\mathrm{n}}$ denote constant only and constant and trend in unit root test equation respectively. Also, observed $R^{2}$ reported for ARCH LM test.

Source: Authors' computation

From Table 2, it can be observed that the highest (peak) and lowest (bottom) return value was recorded in the post-break period. Despite the post-break period having a considerably lower number of observations than the pre-break period, the standard deviation statistic indicates that returns appear to be more volatile in the post-break period. The skewness statistic indicates that returns has a negatively skewed distribution in the sub-sample and full sample periods, thus indicating that there is higher tendency to obtain negative extreme values in returns than positive extreme values. The Kurtosis coefficient indicates returns have a fattailed and highly peaked distribution in the three periods. The Jarque-Bera statistic indicates that the return series is not normally distributed in the pre-break, post-break and full sample periods, hence the Gaussian normal error distribution cannot be assumed for the series in all the periods. The DF-GLS unit root test shows that the return series is a stationary series in all periods. The ARCH LM test rejects the null hypothesis of no ARCH effects in the return series for all periods, thus confirming the presence of return volatility clustering in all the sample periods. The Q-statistic rejects the null hypothesis of no autocorrelation of residuals in the return series of all periods at lag $(k)$ of 2 and 4 except the post-break period. The $\mathrm{Q}^{2}$-statistic indicates that the null hypothesis of no autocorrelation of squared residuals in the return series is rejected for the pre-break and full periods at $k=2$ and 4 while it is only rejected for the post-break period at $k=4$.

Models and Estimation: To determine the persistence and asymmetry of Nigerian stock market volatility, the symmetric (non-asymmetric) and asymmetric volatility model were used. The symmetric volatility model utilised is the symmetric Generalised Autoregressive Conditional Heteroskedasticity (GARCH) model developed by Bollerslev (1986) while the asymmetric volatility model used is the Exponential GARCH (EGARCH) model developed by Nelson (1991).The study built the GARCH $(p, q)$ models in first order because first-order GARCH models are often adequate and widely used in studies on volatility. The models were estimated with the maximum likelihood estimation method. Since the Gaussian error distribution cannot be assumed for return series in all the sample periods due to non-normal distribution, two error distribution alternatives for non-normally distributed series namely Student's $t$-distribution with fixed degree of freedom and Generalised Error Distribution (GED) with fixed parameter were assumed. Using these alternatives, the model that provides the lowest information based on the Schwarz Information Criterion (SC) is considered as the best fit model. From the conducted analyses, the Student's $t$-distribution with fixed degree of freedom 
produced the symmetric and asymmetric models that best fit for the sub-sample and full sample periods. The mean equation for the GARCH $(1,1)$ model in AR(1) form is expressed as:

$$
r_{t}=\varphi+\sum_{n=1}^{k} \rho r_{t-1}+\varepsilon_{t}
$$

Where $\varphi$ is the constant term, $\rho$ is the coefficient of one-period lagged return or immediate past return and $\varepsilon_{t}$ is the residual term.

Symmetric GARCH Model: This study built the symmetric GARCH model to capture the persistence of volatility. The conditional variance equation for the symmetric GARCH $(1,1)$ model is stated as:

$\sigma_{t}^{2}=\omega+\sum_{n=1}^{p} \alpha \varepsilon_{t-1}^{2}+\sum_{n=1}^{q} \beta \sigma_{t-1}^{2}$

Where $\sigma_{t}^{2}$ is conditional variance or market volatility at time $t, \omega$ is the constant parameter, $\alpha$ is the ARCH coefficient indicating short-term volatility persistence and $\beta$ is the GARCH coefficient indicating long-term volatility persistence. The sum of $\alpha$ and $\beta$ measures the persistence of shocks to volatility. The closer the sum to unity, the higher the persistence of shocks to volatility and the longer it would take for conditional variance to converge to its steady state. The summation of $\alpha$ and $\beta$ must not be equal to or exceed unity so that GARCH process does not violate the stationary or mean-reverting condition. Table 3 presents the estimation results of the symmetric GARCH models.

Table 3: Symmetric GARCH Model Estimation Results

\begin{tabular}{|c|c|c|c|}
\hline & Pre-break & Post-break & Full \\
\hline \multicolumn{4}{|l|}{ Mean Equation } \\
\hline$\varphi$ & $1.303730^{*}$ & 0.211256 & 1.429015 \\
\hline$\rho$ & $0.400565^{*}$ & $0.060987^{*}$ & 0.342820 \\
\hline \multicolumn{4}{|c|}{ Variance Equation } \\
\hline$\omega$ & $1.820018^{*}$ & $2.422676^{* * *}$ & $1.762415^{*}$ \\
\hline$\alpha$ & $0.501049 *$ & $-0.215121^{* *}$ & $0.440878^{*}$ \\
\hline$\beta$ & $0.513960^{*}$ & $1.103657^{*}$ & $0.569439 *$ \\
\hline$\alpha+\beta$ & 1.015009 & 0.888536 & 1.010317 \\
\hline \multicolumn{4}{|c|}{ Model Diagnostics } \\
\hline ARCH LM(2) & 0.561327 & 0.290727 & 1.123134 \\
\hline ARCH LM(4) & 2.605425 & 1.145421 & 3.340878 \\
\hline Q-statistic(2) & 0.8262 & 0.3082 & 1.0268 \\
\hline Q-statistic(4) & 2.9152 & 1.3860 & 3.8511 \\
\hline $\mathrm{Q}^{2}$-statistic $(2)$ & 0.5419 & 0.2388 & 1.1335 \\
\hline $\mathrm{Q}^{2}$-statistic $(4)$ & 2.6335 & 1.1911 & 3.4885 \\
\hline
\end{tabular}

Note: ${ }^{*},{ }^{* *}$ and ${ }^{* * *}$ imply statistically significant at $1 \%, 5 \%$ and $10 \%$ significance level. Also, observed $R^{2}$ is reported for ARCH LM test.

Source: Authors' computation

From Table 3, it can be seen that immediate past return has a highly significant positive impact on present return. The ARCH term is statistically significant in all sub-sample and full sample periods, thus indicating volatility clustering in the market in the pre-break, post-break and full sample periods. Also, the GARCH term in the all the periods is statistically significant and this implies that there is long-term persistence of volatility persist in the pre-break, post-break and full sample periods. The post-break period has the highest GARCH coefficient, thus indicating that it takes longer period of time for volatility to die out compared to the prebreak period. The sum of the ARCH and GARCH coefficients in the pre-break and full sample periods is not different from 1 while the sum is close to 1 in the post-break period. The substantial higher number of observations for the pre-break period compared to the post-break period makes it difficult to make a meaningful comparison on the persistence of shocks to volatility in both periods. However, despite the lower 
number of observations in the post-break period, the sum of ARCH and GARCH coefficients tends very close to unity which is evident that the persistence of shocks to volatility is very high. It also shows that returns revert back to the average market returns during this period, thus indicating that the market satisfies the mean reverting condition in the post-break period. The sum of the ARCH and GARCH coefficients in the full sample period is approximately equal to 1 , thus implying that shocks to volatility are extremely persistent and the market follows an integrated GARCH (IGARCH) or non-stationary process. When a market follows an IGARCH process, it means unconditional variance becomes infinite and this implies that positive shocks (good news) or negative shocks (bad news) would have permanent effect on future volatility.

EGARCH Model: The EGARCH model ensures that conditional variance is non-negative even when the model parameters are negative. This is because the model measures conditional variance in logarithm form. Though the model has the power to measure volatility persistence, this study built uses the EGARCH model to only capture response of volatility to asymmetry. The EGARCH $(1,1)$ model is expressed as:

$\ln \left(\sigma_{t}^{2}\right)=\omega+\sum_{n=1}^{p} \propto\left|\frac{\varepsilon_{t-1}}{\sqrt{\sigma_{t-1}^{2}}}\right|+\sum_{n=1}^{r} \gamma \frac{\varepsilon_{t-1}}{\sqrt{\sigma_{t-1}^{2}}}+\sum_{n=1}^{q} \beta \ln \left(\sigma_{t-1}^{2}\right)$

In this model, $\gamma$ is the asymmetry term coefficient and there is asymmetry when $\gamma \neq 0$.Leverage effect can be tested with the hypothesis that $\gamma<0$. To accept this hypothesis, $\gamma$ must be negative and statistically significant. Leverage effect implies that bad news such as fall in return makes stock riskier, thus leading to increase in volatility. The evidence of leverage effect means that bad news increases volatility than good news of the same size. On the other hand, if $>0$, it implies good news increases volatility than bad news of equal magnitude. The total impact of good news and bad news are $\alpha+\gamma$ and $\alpha-\gamma$ respectively. The model is covariance stationary when the coefficient of $\ln \left(\sigma_{t-1}^{2}\right)<1$. Table 4 presents the estimation results of the EGARCH models.

Table 4: EGARCH Model Estimation Results

\begin{tabular}{clll}
\hline & Pre-break & Post-break & Full \\
\hline Mean Equation & & & \\
$\varphi$ & $1.228902^{*}$ & 0.213599 & $1.327072^{*}$ \\
$\rho$ & $0.399684^{*}$ & 0.029468 & $0.350789^{*}$ \\
Variance Equation & & & \\
$\omega$ & -0.071013 & $0.519118^{*}$ & -0.091968 \\
$\alpha$ & $0.668967^{*}$ & $-0.366942^{* * *}$ & $0.621075^{*}$ \\
$\gamma$ & -0.049343 & -0.003836 & -0.058665 \\
$\beta$ & $0.846980^{*}$ & $0.923189^{*}$ & $0.873861^{*}$ \\
$\propto+\gamma$ & 0.619624 & -0.370778 & 0.56241 \\
$\propto-\gamma$ & 0.718310 & 0.363106 & 0.67974 \\
Model Diagnostics & & & \\
ARCH LM(2) & 0.710195 & 0.627750 & 1.413335 \\
ARCH LM(4) & 5.043130 & 2.135012 & 5.621939 \\
Q-statistic(2) & 1.0712 & 0.5851 & 1.6347 \\
Q-statistic(4) & 2.9512 & 1.2422 & 5.1361 \\
$\mathrm{Q}^{2}$-statistic(2) & 0.6555 & 0.6712 & 1.4343 \\
$\mathrm{Q}^{2}$-statistic(4) & 4.8672 & 2.2856 & 5.9650 \\
\hline
\end{tabular}

Note: ${ }^{*},{ }^{* *}$ and ${ }^{* * *}$ imply statistically significant at $1 \%, 5 \%$ and $10 \%$ significance level. Also, observed $\mathrm{R}^{2}$ reported for ARCH LM test.

Source: Authors' computation

From Table 4, it can be seen that the coefficient of the asymmetry term is negatively signed but not statistically significant in the pre-break, post-break and full sample periods, thus indicating that there is absence of asymmetric volatility in the market. It also reveals that there is absence of leverage effect in the market in all the periods. It is evident that returns volatility in the Nigerian stock market is non-asymmetric with or without structural break. 


\section{Conclusion}

This study examined the persistence and asymmetry of Nigerian stock market volatility with structural break using symmetric and asymmetric GARCH models. The test for structural break indicated that break occurred in the market in December 2008. With the aid of symmetric GARCH model, the GARCH coefficient in the postbreak period is higher compared to the pre-break period, thus indicating that volatility takes a longer period to decay in the post-break period. However, the sum of the ARCH and GARCH coefficients indicates that persistence of shocks to volatility is higher in the pre-break period. This may be due to the larger number of observations in the pre-break period. The EGARCH model which is an asymmetric variant of GARCH model revealed that returns volatility is non-asymmetric in the pre-break, post-break and full periods. This implies that there is absence of leverage effect with or without accounting for structural break in the Nigerian stock market. On a whole, the study showed that returns volatility in the Nigerian stock market is explosive and affected by good and bad news symmetrically, and the market follows an IGARCH process which indicates that good or bad news have permanent effect on volatility in future periods. This study concludes that the Nigerian stock market is characterised by inefficiency, high degree of uncertainty and non-asymmetric volatility. The high volatile nature of the Nigerian stock market poses great threat to domestic and foreign portfolio investment; hence government should consistently implement policy reforms that boost investors' market confidence.

\section{References}

Abdalla, S. Z. S. \& Winker, P. (2012). Modelling stock market volatility using univariate GARCH models: Evidence from Sudan and Egypt. International Journal of Economics and Finance, 4(8), 161-176.

Adesina, K. S. (2013). Modelling stock market return volatility: GARCH evidence from Nigerian Stock Exchange. International Journal of Financial Management, 3(3), 38-46.

Ahmed, A. M. A. \& Suliman, S. Z. (2011). Modelling stock market volatility using GARCH models evidence from Sudan. International Journal of Business and Social Science, 2(23), 114-128.

Atoi, N. V. (2014). Testing volatility in Nigeria stock market using GARCH models.CBN Journal of Applied Statistics, 5(2), 65-93.

Banumathy, K. \& Azhagaiah, R. (2015). Modelling stock market volatility: evidence from India. Managing Global Transitions, 13(1), 27-42.

Boako, G., Agyemang-Badu, A. A. \& Frimpong, J. M. (2015). Volatility dynamics in equity returns: A multiGARCH approach. European Journal of Business and Innovation Research, 3(4), 36-45.

Bollerslev, T. (1986). Generalised autoregressive conditional heteroskedasticity. Journal of Econometrics, 31, 307-327.

Bundo, S. K. (2011). Asset price developments in an emerging stock market: The case of Mauritius (AERC Research Paper 219). Nairobi: African Economic Research Consortium.

Coffie, W. (2015). Modelling and forecasting the conditional heteroskedasticity of stock returns using asymmetric models: Empirical evidence from Ghana and Nigeria. Journal of Accounting and Finance, 15(5), 109-123.

Emenike, K. O. (2010). Modelling stock returns volatility in Nigeria using GARCH models (MPRA Paper No. 23432). Retrieved from http://mpra.ub.uni-muenchen.de/23432/.

Emenike, K. O. \& Aleke, S. F. (2012). Modelling asymmetric volatility in the Nigerian Stock Exchange. European Journal of Business and Management, 4(12), 52-59.

Gabiax, X., Gopikrishnan, P., Plerou, V. \& Stanley, H. E. (2006). Institutional investors and stock market volatility. The Quarterly Journal of Economics, 5, 461-504.

Guo, H. (2002). Stock market returns, volatility, and future output. Federal Reserve Bank of St. Louis, September/October, 75-86.

Goudarzi, H. \& Ramanarayanan, C. S. (2010). Modelling and estimation of volatility in the Indian stock market. International Journal of Business and Management, 5(2), 86-98.

Harvey, R. C. (1995). Predictable risk and returns in emerging markets. The Review of Financial Studies, 8(3), 773-816.

Karolyi, G. A. (2001). Why stock return volatility really matters. Institutional Investor Journal Series, February. Paper presented for Inaugural Issue of Strategic Investor Relations. 
Kumar, D. \& Maheswaran, S. (2012). Modelling asymmetry and persistence under the impact of sudden changes in the volatility of the Indian stock market. IIMB Management Review, 24, 123-136.

Kupiec, P. (1991). Stock market volatility in OECD countries: Recent trends. Consequences for the real economy and the proposals for reform. Economic Studies, 17, 32-60.

Lamoureux, C. G. \& Lastrapes, W. D. (1990). Persistence in variance, structural change and the GARCH model. Journal of Business and Economics Statistics, 68, 225-234.

LeRoy, S. F. \& Porter, R. D. (1981). The present-value relation: Tests based on implied variance bounds. Econometrica, 49, 555-574.

Li, Q., Yang, J., Hsiao, C. \& Chang, Y. (2005).The relationship between stock returns and volatility in international stock markets. Journal of Empirical Finance, 12, 650-665.

Mele, A. (2008). Understanding stock market volatility - A business cycle perspective. London: London School of Economics.

Namugaya, J., Weke, P. G. O. \& Charles, W. M. (2014). Modelling stock returns volatility on Ugandan Securities Exchange. Applied Mathematical Sciences, 8(104), 5173-5184.

Ndwiga, D. \& Muriu, P. W. (2016). Stock returns and volatility in an emerging equity market: Evidence from Kenya. European Scientific Journal, 12(4), 79-98.

N'dri, K. L. (2007). Stock market returns and volatility in the BRVM. African Journal of Business Management, 1(5), 107-112.

Niyitegeka, O. \& Tewari, D. D. (2013). Volatility clustering at the Johannesburg Stock Exchange: Investigation and analysis. Mediterranean Journal of Social Sciences, 4(14), 621-626.

Nelson, D. (1991). Conditional heteroscedasticity in asset returns: A new approach. Econometrica, 59(2), 347370.

Oloko, T. F. (2016). Portfolio diversification between developed and less developed economies: The case of US and UK investors in Nigeria (CSEA Working Paper WPS/16/02). Abuja: Centre for the Study of Economies of Africa.

Osazevbaru, H. O. (2014). Measuring Nigerian stock market volatility. Singaporean Journal of Business Economics and Management Studies, 2(8), 1-14.

Owidi, O. H. \& Mugo-Waweru, F. (2016).Analysis of asymmetric and persistence in stock return volatility in the Nairobi Securities Exchange market phases. Journal of Finance and Economics, 4(3), 63-73.

Perron, P. (1997). Further evidence on breaking trend functions in macroeconomic variables. Journal of Econometrics, 80, 335-385.

Perron, P. (2006). Dealing with structural breaks. In Palgrave Handbook of Econometrics, 1, 278-352.

Shiller, R. J. (1981). Do stock prices move too much to be justified by subsequent changes in dividends? American Economic Review, 71(3), 421-435.

Shiller, R. J. (2003). From efficient markets theory to behavioural finance. Journal of Economic Perspectives, 17(1), 83-104.

Shittu, O. I., Yaya, O. S. \& Oguntade, E. S. (2009). Modelling volatility of stock returns on the Nigerian stock exchange. Global Journal of Mathematics and Statistics, 1(2), 87-94.

Turtle, H. J. \& Zhang, C. (2014).Structural breaks and portfolio performance in global equity markets. Faculty Publications-School of Business, Paper 52. Retrieved from http://digitalcommons.georgefox.edu/gfsb/52.

Wang, Y. \& Ma, J. (2014).Excess volatility and the cross-section of stock returns. North American Journal of Economics and Finance, 27, 1-16. 